\title{
PEMBANGUNAN BERKELANJUTAN KAWASAN PESISIR DI KABUPATEN BATUBARA PROVINSI SUMATERA UTARA
}

\section{Sustainable Development in the Coastal Area of Batubara Distric Province of Sumatera Utara}

\begin{abstract}
Nurmatias
Dosen Manejeman sumberdaya perairan, Universitas Sumatera Utara, Medan.
\end{abstract}

\section{Abstract}

This study was conducted in the coastal area of Batubara District from May to October 2010. Doing a survey to 342 respondents, the data collected were related to the elements of sustainable development Such as environmental, economic, and socio cultural aspects. To examine the development as a whole, the data obtained were analyzed through Structural Equation Model (SEM), GAP analysis was used to look at the accomplishment of the existing development, SWOT analysis was used to Prepare the srategy of sustainable development, and descriptive analysis was used to empower the natural resources.

The concept and the principle of sustainable ddvelopment has not been applied in the development of coastal area of Batubara District. It is proven through the incident of environmental degradation, the not-yet met conservation program, the high poverty rate, the not-yet created equitable income distribution and new job opportunities, still-low education level of community, non-referring to the sustainable development existing institutions, and local wisdom-left cultural shifts.

The development looking at partially will never be sustainable. The result of the development only looking at the social and economic aspects will only for equalization. If the development looking at environmental and social aspects, the result will only for convenience, and the development looking at economic and environmental aspects only will result in the environmental which will bear a burden. Yet, if the development holistically looks at the environmental, economic and socio-cultural aspects, the sustainable development will be created.The strategy for the development of coastal area of Batubara 
District is to plan the use of natural resources as the economic resource to create welfare for the current communities and future generation.

Keywords: Development, Sustainable, Holistic.

\section{Abstrak}

Penelitian dilakukan di kawasan pesisir kabupaten Batubara dari bulan Mei sampai Oktober 2010, menggunakan metode survey kepada 342 responden, Data yang dikumpul adalah unsur pembangunan berkelanjutan yaitu aspek lingkungan, aspek ekonomi dan aspek sosial budaya. Analisis data yang digunakan adalah; Structural Equatian Modeling (SEM), untuk melihat pembangunan secara keseluruhan, GAP analisis unluk melihat capaian pembangunan saat ini, dan SWOT analisis untuk menyusun strategi pembangunan berkelanjutan, sedangkan untuk melihat pendayagunaan sumberdaya alam menggunakan analisis diskripsi.

Pembangunan kawasan pesisir kabupaten Batubara belum menerapkan konsep dan prinsip pembangunan berkelanjutan. Hal ini dibuktikan dari terjadinya degredasi lingkungan, belum dijumpai program konservasi, tingginya angka kemiskinan, belum terciptanya pemerataan pendapatan dan lapangan kerja baru, tingkat pendidikan masyarakat masih rendah, kelembagaan yang ada tidak mengacu pada pembangunan berkelanjutan, terjadinya pergeseran budaya yang meninggalkan kearifan lokal.

Pembangunan secara parsial seperti pembangunan hanya memperhatikan aspek sosial dan ekonomi saja hasilnya hanya untuk pemerataan, jika pembangunan memperhatikan lingkungan dan sosial hasilnya hanya untuk kenyamanan sedangkan pembangunan yang memperhatikan ekonomi dan lingkungan hasilnya lingkungan akan menanggung beban. Tetapi jika pembangunan memperhatikan secara holistik dari aspek lingkungan, aspek ekonomi, dan aspek sosial budaya maka tercipta pembangunan berkelanjutan.

Strategi pembangunan kawasan pesisir kabupaten batubara adalah merencanakan penggunaan sumberdaya alam sebagai sumber 
ekonomi untuk menciptakan kesejahteraan masyarakat saat ini dan generasi yang akan datang.

Kata kunci: Pembangunan, berkelanjutan, holistic.

\section{PENDAHULUAN}

Pembangunan pada hakikatnya adalah suatu upaya sadar yang dilakukan oleh manusia untuk meningkatkan kualitas hidup dan angkat kesejahteraannya. Keberhasilan pembangunan sangat ditentukan oleh sumberdaya manusia, sumberdaya alam, modal dan teknologi.

Konsep pembangunan lndonesia pada orde baru memakai prinsip trilogi pembangunan (stabilitas nasional, pertumbuhan ekonomi dan pemerataan pembangunan). Konsep ini belum dapat mengangkut kesejahteraan masyarakat khususnya di kawasan pesisir, akan tetapi menimbulkan disparitas pembangunan, sebab pembangunan yang dilakukan masalah bertumpu pada memanfaatkan sumberdaya alam tanpa memperhatikan lingkungan dan sosial ekonomi masyarakat yang akan menikmati pembangunan tersebut.

Kelemahan konsep pembangunan selama ini adalah; kurang memperhatikan lingkungan dan kebutuhan generasi yang akan datang. Melihat kenyataan tersebut, PBB pada konverensi tingkat tinggi bumi di Rio Jeneiro bulan juli 1992 merumuskan pembangunan kedepan dan membuat program kerja tentang "Pembangunan Berkelanjutan" yang tertuang dalam "Agenda 2l".

Pembangunan berkelanjutan menurut Soemorwoto 12007) adalah; pembangunan yang direncanakan secara sistimatik dan terpadu demi rnemenuhi kebutuhan saat sekarang tanpa mengurangi kebutuhan generasi yang akan datang. Sedangkan Salim (1993) mendefinisikan pembangunan brrkelanjutan adalah suatu proses yang mengoptimalkan manfaat dan menyelerasikan sumberdaya alam dan sumberdaya manusia dalam pembangunan.

Menurut Ahmad (2008) kesejahteraan di kawasan pesisir akan tercapai jika menerapkan prinsip pembangunan berkelanjutan. 
Kerangka kerjanya adalah mengoptimalkan pemanfaatkan sumber daya lingkungan hidup, usaha yang dilakukan menguntungkan atau efisiensi secara ekonomi dan membawa pengaruh pada kemakmuran, kesejukan bagi masyarakat yang berada di dalamnya. Pembangunan berkelanjutan di wilayah pesisir didefinisikan sebagai kemampuan suatu pembangunan untuk mencapai kesejahteraan secara terus menerus berkelanjutan sampai ke generasi yang akan datang. Sedangkan program pembangunan berkelanjutan di kawasan pesisir adalah memadukan tiga sasaran utama yakni: pembangunan wilayah pesisir yang memperhatikan lingkungan, kegiatan ekonomi yang menguntungkan, mensejahterakan dan memakmurkan masyarakat secara adil berkelanjutan sampai ke generasi berikutnya (Galton et al, 2000).

Pembangunan berkelanjutan dilakukan dengan pendekatan keruangan (spatial), dengan memperhatikon aspek lingkungan, ekonomi dan sosial budaya. Tujuan dari aspek lingkungan terjaganya keseimbangan ekosistem, ekonomi adalah upaya peningkatan kesejahteraan dan kemakrnuran semaksimal mungkin dan aspek sosial budaya adalah terbentuknya demokratisasi, pemberdayaan, transparansi dan keutuhan budaya (Kuswatojo, 2000).

Melihat pola pembangunan yang telah dilaksanakan selama ini di kawasan pesisir kabupaten Batubara dan mencermati prinsip pembangunan berkelanjutan, maka penelitian ini mencoba mengkaji penerapan pembangunan berkelanjutan untuk di kawasan pesisir kabupaten Batubara.

Berdasarkan uraian di atas serta fakta-fakta yang ditemukan dilapangan, dan melihat keterkaitan antara aspek lingkungan, ekonomi dan sosial budaya sebagai penentu dari pembangunan berkelanjutan peneliti tertarik melakukan penelitian dengan judul "Pembangunan Bekelanjutan Kawasan Pesisir di Kabupaten Batubara Provinsi Sumatera Utara. 


\section{METODE PENELITIAN}

Penelitian ini dilaksanakan dari 22 Mei sampai 21 Oktober 2010 meliputi keseluruhan rangkaian kegiatan: dimulai dari penyusunan proposal, turun kelapangan, analisis data, penulisan hasil. Lokasi penelitian ditetapkan di wilayah pesisir kabupaten Batubara yaitu Kecamatan Medang Deras,kecamatan Limapuluh, Kecamatan Tanjung Tiram, Kecamatan Talawi, dan kecamatan Suka. Penetapan lokasi ini atas dasar pertimbangan bahwa hanya lima kecamatan ini punya kawasan pesisir. Lokasi penelitian adalah seluruh desa/kelurahan berada searah garis pantai yang berhadapan langsung dengan selat Melaka di lima kecamatan tersebut.

Rancangan yang dipakai dalam penelitian ini adalah konklusif yang berfungsi untuk menggambarkan karakteristik/gejala/fungsi suatu populasi dan mengidentifikasi hubungan sebab dan akibat atara variabel-variabel yang berfungsi sebagai penyebab (variabel bebas) dan variabel akibat (variabel tergantung).

Metode penelitian menggunakan metode survey dan studi lapangan Metode berupaya mencari informasi sebanyak mungkin dan beragam dengan cara pengamatan langsung (observasi) angket wawancara dan diskusi di lokasi. Sedangkan tujuan dari metode penelitian ini adalah asosiatif dan explanotori. Asosiotif yaitu mengetahui hubungan antara dua variabel atau lebih sedangkan explanotori adalah untuk mencari dan menjelaskan hubungan kausal antara variabel melalui pengujian hipotesis.

Objek penelitian adalah orang-orang yang dapat mengamati dan melihat hasil pembangunan yang dilaksanakan di kawasan pesisir Kabupaten Batubara selama ini. Indikotor pembangunan hanya terbatas pada beberapa aspek yakni; Aspek lingkungan, dilihat dari keseimbangan lingkungan, pemanfaatan lingkungan yang efisiensi, kestabilan lingkungan dan tingkat dan pemanfaatan sumber terhadap daya dukung; aspek ekonomi dilihat dari pertumbuhan ekonomi, kemiskinan dan pendapatan; aspek sosial dilihat dari tingkat pendidikan, kesehatan dan kelembagaan serta budaya masyarakat. Sedangkan pembangunan berkelanjutan dilihat dari kestabilan 
ekonomi, terjaganya lingkungan, terjaganya keamanan serta berkembangnya demokrosi dan partisipasi masyarakat.

Tehnik pengambilan sampel dilakukan dengan cara sampling bertahap. Tahap pertama adalah menentukan daerah/lokasi. Daerah penelitian adalah desa/kelurahan yang memiliki garis pantai/berhubungan dan berhadapan langsung dengan Selat Melaka. Tahap kedua menetapkan jumlah sampel di masing-masing daerah berdasarkan jumlah penduduk. Jumlah sampel yang digunakan sebanyak 267 berdasarkan analisis statistik dan ditambah 75 sampel dari pelajar. Sampel pelajar hanya untuk mengetahui kondisi dan sistem pembelajaran yang ada saat ini. Tahap ketiga menentukan orang yang akan dijadikan sebagai responden sesuai dengan kriteria yang di tetapkan. Teknik yang digunakan adalah teknik purposive sampling. Tahap keempat (akhir) adalah enumerator mendatangi responden langsung ke alamat/tempat yang bersangkutan untuk mengisi daftar pertanyaan dan interview, sesuai dengan ketentuan dan jumlah dari masing-masing elemen masyarakat. Pengisian kuesioner dilakukan pada saat responden tidak melakukan kegiatan rutin. Pengisian kuesioner oleh responden di tunggu oleh enumerator sampai selesai.

Format kuesioner (pertanyaan dan jawaban) disusun sedemikian rupaadengan harapan responden dapat menunjukkan sikap positif dan memahami terhadap hal yang ditanyakan, dan mempengaruhi responden agar suka dan rela membantu peneliti dalam menemukan hal yang akan dicari dalam penelitian ini.

penyusunan butiran-butiran instrument dimulai dari merinci variabel menjadi sub-variabel, kemudian menjadi indikator dan descriptor lalu menjadi butiran instrument (pertanyaan). Pertanyaan tertutup disusun dengan pilihan jawaban dengan menggunakan skala, hal ini bertujuan untuk memungkinkan responden menjawab berdasarkan tingkatan penilaian atau pilihan responden. Pengukuran menggunakan angka-angka yang ditetapkan sesuai dengan ciri-ciri sosial, fsikologis dari individu atau kelompok. Ciri-ciri tersebut akan dihubungkan dengan ongkos yang merupakan simbol atau nilai dari ungkapan yang diberikan responden untuk mengekspresikan perasaannya. 
Teknik yang dipakai dalam penelitian ini adalah pemberian skala angka pada objek atau kejadian yang sedang diamati. Skala pengukuran yang akan digunakan dalam penelitian ini adalah Skala Likert skala ini digunakan unluk menentukan sikap. Kriteria penilaian kuesioner yang di aiukan adalah : Nilai I Sangat tidak setuju, nilai 2 Tidak setuju, nilai 3 Kurang setuju. Nilai 4 Setuiu dan nilai 5 Sangat setuju.

Variabel penelitian ini terdiri dari tiga variabel eksogen dan satu variabel endogen. Variabel eksogen adalah; Aspek lingkungan, aspek ekonomi dan aspek sosial budaya, sedangkan variabel endogen adalah pembangunan berkelanjutan.

Uji validasi menggunakan bantuan program Statistical product and Service Solutiont (SPSS) for Windows, yang dilakukan secera acak pada 45 orang responden sebelum di sampaikan ke responden di kawasan pesisir kabupaten Batubara.

Uji reliabilitas adalah untuk mengukur tingkat konsisten instrumen yang digunakan, dengan harapan instrumen yang digunakan dapat dipakai dengan aman walaupun pada waktu dan kondisi yang berbeda. Uji reliabililas dilakukan dengan menghitung nilai alfa atau Cronbach's Alpha, yaitu dengan cara menghitung rata-rata interkorelasi di antara butir-buiir pernyataan dalam kuesioner, dengan menggunakan bantuan program Statistical product and Service Solutiont (SPSS) for Windows. Apabila Cronbach's Alpha kurang dari 0,60 dinyatakan kurang, tetapi jika Cronbach's Alpha sebesar 0,70 dinyatakan dapat diterima sedangkan jika Cronbach's Alpha besar dari 0,80 dinyatakan baik (Trihendradi, 2006).

Untuk menguji hubungan antar variabel dan melihat model pembangunan secara keseluruhan menggunakan Structural Equation Modeling (SEM). Sedangkan untuk melihat validitas dan reliabilitas menggunakan Statistical product and Service Solutiont (SPSS).

Membandingkan capaian pembangunan saat ini dengan yang seharusnya dicapai menggunakan GAP analisis. Analisis ini memperbandingkan capaian pembangunan saat ini dengan yang seharusnya di capai agar terjadi pembangunan berkelanjutan. 
Perencanaan yang akan disusun dalam laporan ini adalah perencanaan strategi. Untuk menyusun strategi pembangunan berkelanjutan digunakan analisis SWOT (strength, weakness, opportunity, threat, analysis). Analisis ini akan menemukan isu strategis yang nantinya akan digunakan untuk menyusun strategi pembangunan berkelanjutan di kawasan pesisir Kabupaten Batubaru.

Strategi yang diambil adalah menggunakan kekuatan untuk menangkap kesempatan, mengatasi kelemahan dengan mengambil kesempatan, menggunakan kekuatan untuk menghindari ancaman, meminimalkan kelemahan dengan menghindari ancaman. Untuk melihat pendayagunaan sumberdaya terhadap implementasi pembangunan menggunakan analisis diskripsi.

\section{HASIL DAN PEMBAHASAN}

\section{Analisis Structure Equation Modeling (SEM)}

Dari hasil analisis secara keseleruhan dapat dilihat bahwa lingkungan memberi kontribusi sebesar $56,2 \%$ terhadap pembangunan berkelanjutan, ekonomi sebesar $71,1 \%$ terhadap pembangunan berkelanjutan sedangkan sosial budaya memberi kontribusi sebesar $75,9 \%$ terhadap pembangunan berkelanjutan, hal ini dapat dilihat pada Gambar 1.

Secara bersamaan aspek lingkungan dan aspek ekonomi mempunyai pengaruh positif terhadap pembangunan berkelanjutan, sosial budaya memberi pengaruh negatif terhadap pembangunan berkelanjutan. Aspek lingkungan memberi pengaruh positif terhadap pembangunan berkelanjutan dengan koefisien 0.562 artinya jika aspek lingkungan meningkat satu-satuan kearah yang lebih baik maka akan meningkat kualitas pembangunan berkelanjutan sebesar 0.562 satuan. Begitu juga dengan aspek ekonomi memberi nilai positif terhadap pembangunan berkelanjutan dengan koefisien sebesar 0.711 , artinya apabila aspek ekonomi meningkat satu-satuan maka pembangunan berkelanjutan akan naik sebesar 0.711 satuan. Berbeda dengan sosial budaya mempunyai pengaruh negatif terhadap pembangunan berkelanjutan dengan koefisien 0.759 . Artinya jika sistim budaya yang 
ada saat ini dikembangkan per satu-satuan maka akan menurunkan pembangunan berkelanjutan sebesar 0.759 satuan.

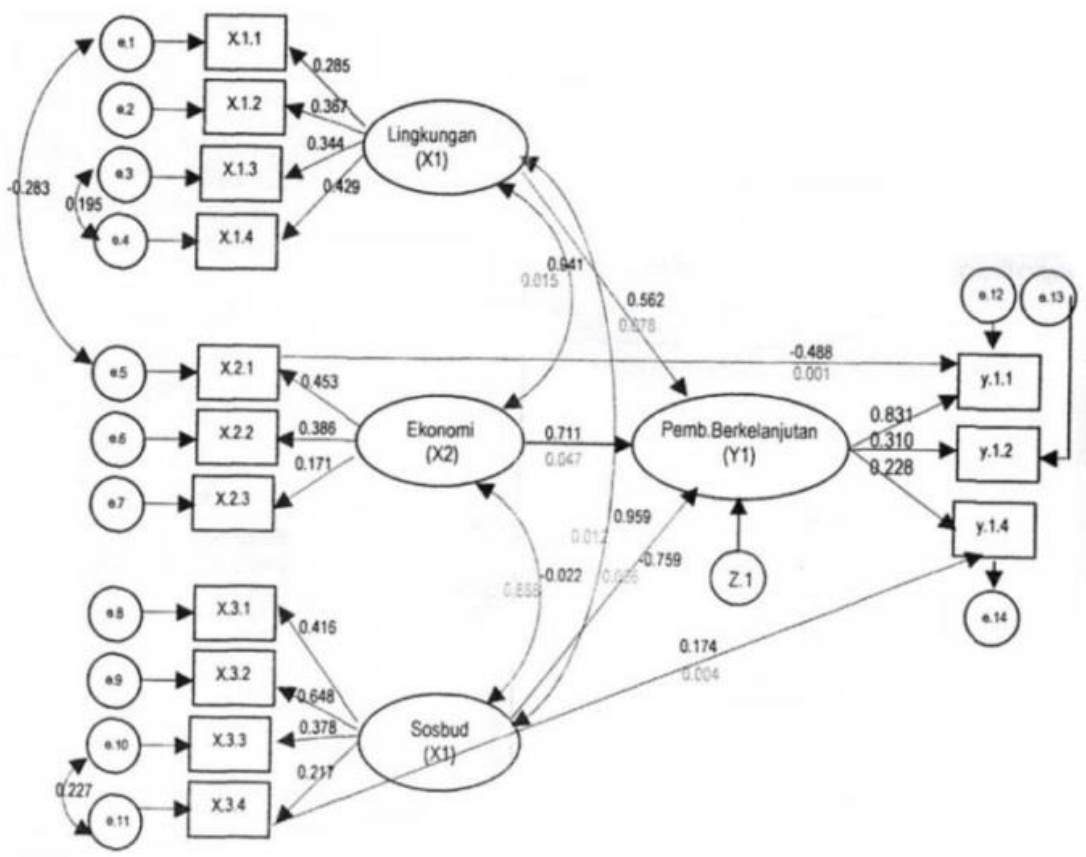

Gambar 1 Model hasil analisis SEM dari masing-masing indicator dan variabel penelitian.

Selain variabel lingkungan,ekonomi dan sosial budaya ternyata ada hubungan yang kuat antara pertumbuhan ekonomi (X2.1) dengan degredasi lingkungan (Y.11) dan budaya (X3.4) dengan partisipasi (Y1.4) yang merupakan indikator dari pembangunan berkelanjutan. Dari hasil analisis diketahui bahwa pertumbuhan ekonomi memberi kontribusi terhadap degredasi lingkungan sebesar $48.8 \%$, sedangkan budaya masyarakat memberi kontribusi terhadap partisipasi sebesar $17.4 \%$.

Indikator pertumbuhan ekonomi berpengaruh negative terhadap degredasi lingkungan untuk saat ini, dengan koefisien -0.488 , artinya jika terjadi pertumbuhan ekonomi per satu-satuan maka akan 
mengurangi degredasi sebesar 0.488 satuan. Sedangkan budaya berpengaruh positif terhadap partisipasi dengan koefisien 0.174. Artinya jika budaya saat ini dinaikkan per satu-satuan maka akan meningkatkan partisipasi masyarakat.

Kesimbangan lingkungan mempunyai hubungan sebesar $-28.3 \%$ dengan pertumbuhan ekonomi, hubungsn antara daya dukung lingkungan terhadap efisiensi sebesar $19.5 \%$ dan hubungan antara kelembagaan dengan budaya sebesar $22.77 \%$.

\section{Pengujian Hipotesis}

Hasil uji hipotesis dengan menggunakan tingkat kepercayaan $10 \%$ maka ketiga aspek lingkungan, ekonomi, sosial budaya mempunyai pengaruh terhadap pembangunan berkelanjutan. hasil dari $\mathrm{F}$ hitung untuk masing-masing aspek adalah ; aspek lingkungan dengan sig. 0.078, aspek ekonomi dengan sig. 0.047 dan aspek sosial budaya dengan sig. 0.066 berarti ketiga aspek ini lebih kecil dari 10\%, dengan demikian seluruh aspek mempunyai pengaruh yang signifikan terhadap pembangunan berkelanjutan.

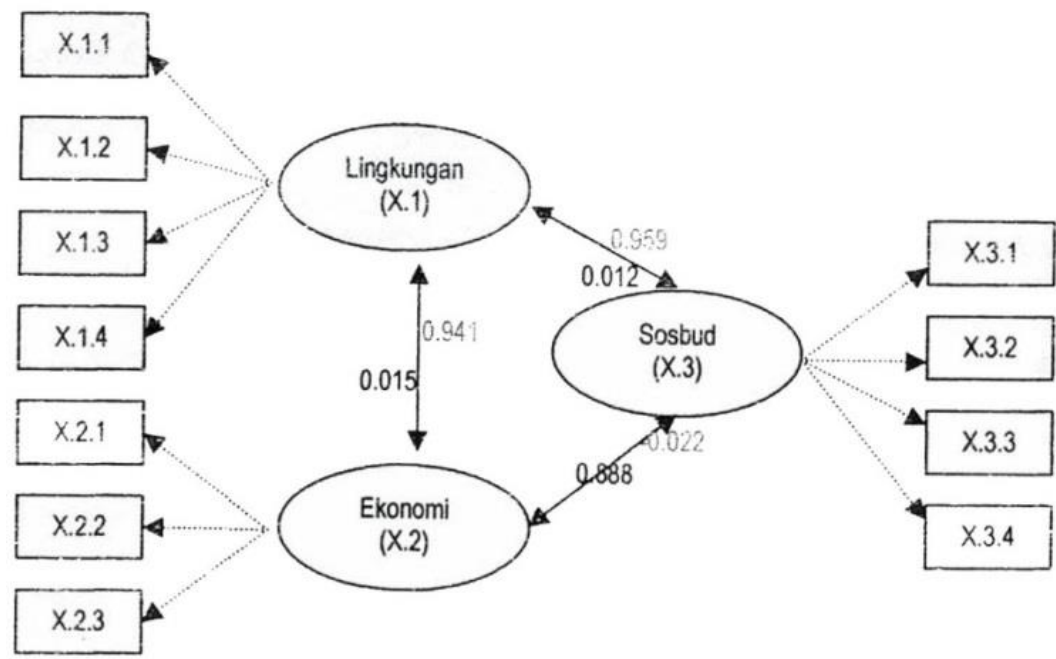

Gambar 2 Skema hubungan dan pengaruh antar variabel pengamanan. 


\section{Analisis (GAP)}

\section{Tabel 1: Kondisi Lingkungan di kawasan pesisir kabupaten Batubara.}

\section{a. Keseimbangan Lingkungan Kawasan Pesisir Kabupaten Batubara}

\begin{tabular}{|l|l|c|r|r|}
\hline No & lndikator & Satuan & Standar & Eksisting \\
\hline \multirow{7}{*}{} & Luas hutan & $\%$ & $>50$ & 14 \\
\cline { 2 - 5 } & Luas Hutan Bakau & $\%$ & $>35$ & 4 \\
\cline { 2 - 5 } & Tutupan Hutan Bakau & $\%$ & $>60$ & 22 \\
\cline { 2 - 5 } & Standing Stock Ikan & Ton & 8.569 & 17800 \\
\cline { 2 - 5 } & Abrasi Pantai & $\%$ & 0 & 90 \\
\cline { 2 - 5 } & a. Jarak abrasi pantai & M & 0 & $>500$ \\
\cline { 2 - 5 } & b. Tahun dirasakan & $\%$ & - & 1985 \\
\cline { 2 - 5 } & Intruksi air laut & M & 0 & 24 \\
\cline { 2 - 5 } & a. Jarak intrusi & tahun & - & 2000 \\
\cline { 2 - 5 } & b. Tahun dirasakan & & &
\end{tabular}

\section{b. Kestabilan Lingkungan kawasan Pesisir Kabupaten Batubaru}

\begin{tabular}{|l|l|c|l|l|}
\hline No & lndikator & Satuan & Standar & Eksisting \\
\hline \multirow{8}{*}{} & Penyebaran ikan & $\%$ & Merata & Tidak merata \\
\cline { 2 - 5 } & Dominasi & $\%$ & kosmopolit & Ikan musna \\
\cline { 2 - 5 } & Produksi/operasional & $\mathrm{Kg}$ & Normal & Musiman \\
\cline { 2 - 5 } & produksi & $\mathrm{Kg}$ & naik & Turun \\
\cline { 2 - 5 } & a. Tahun penurunan & Tahun & 0 & 2000 \\
\cline { 2 - 5 } & b. Ukuran tertangkap & Panjang & normal & mengecil \\
\hline
\end{tabular}

\section{c. Daya dukung lingkungan kawasan pesisir kabupaten batubara}

\begin{tabular}{|l|l|c|r|r|}
\hline No & \multicolumn{1}{|c|}{ Indikator } & Satuan & Standar & Eksisting \\
\hline 1 & Pemanfaatan perikanan tangkap & $\%$ & Seimbang & Kurang \\
\hline 2 & Pemanfaatan lahan budidaya ikan & $\%$ & $<30$ & 2,78 \\
\hline 3 & Produk tambak intensif & $\mathrm{Kg} / \mathrm{Ha}$ & $>5.000$ & 3.275 \\
\hline 4 & Produk tambak tradisional & $\mathrm{Kg} / \mathrm{Ha}$ & $>3.000$ & 526 \\
\hline 5 & Luas lahan sawah & $\mathrm{Ha} / \mathrm{org}$ & $>0,5$ & 0,125 \\
\hline 6 & Luas lahan dapat dikembangkan & $\%$ & Tersedia & $<23$ \\
\hline 7 & Produk padi sawah (GKP) & Ton & $>6$ & 6,5 \\
\hline 8 & Musim tanam padi & Kali/Thn & 2 & 2 \\
\hline 9 & Tadah hujan & $\%$ & 0 & 78 \\
\hline
\end{tabular}




\section{d. Tingkat efesiensi pemanfaatan lingkungan}

\begin{tabular}{|l|l|r|r|r|}
\hline \multirow{2}{*}{ No } & \multicolumn{1}{|c|}{ Bidang usaha } & \multicolumn{2}{c|}{ Tahun } & \multirow{2}{*}{ Nilai } \\
\cline { 3 - 5 } & & \multicolumn{1}{|c|}{ Out put } & \multicolumn{1}{c|}{ In put } & \\
\hline 1 & Nelayan & & & \\
\cline { 2 - 5 } & a. Tradisional & 8.755 .728 & 7.963 .544 & 1,10 \\
\cline { 2 - 5 } & b. Bermotor & 29.903 .928 & 64.354 .542 & 0,46 \\
\cline { 2 - 5 } & Petambak udang & & & \\
\hline \multirow{2}{*}{2} & a. Tradisional & 262.071 .276 & 238.985 .342 & 1,10 \\
\cline { 2 - 5 } & b. Intensif & & & \\
\hline 3 & Petani & 23.845 .788 & 19.836 .443 & 1,20 \\
\cline { 2 - 5 } & a. Tanam padi & 37.693 .032 & 26.002 .973 & 1,45 \\
\cline { 2 - 5 } & b.Perkebunan sawit & 20.229 .000 & 18.988 .590 & 1,07 \\
\cline { 2 - 5 } & c. Perkebunan karet & 29.000 .700 & 7.800 .450 & 3,72 \\
\cline { 2 - 5 } & d.Perkebunan kelapa & 51.906 .900 & 48.584 .114 & 1,07 \\
\cline { 2 - 5 } & e.Perkebunan coklat & & & \\
\hline
\end{tabular}

Sumber : Data Primer

\section{Tabel 2 : Kondisi Ekonomi di Kawasan Pesisir Kabupaten Batubara}

a. Pendapatan Masyarakat dan Pertumbuhan Pendapatan tahun 2009 $-2010$.

\begin{tabular}{|c|c|c|c|c|c|}
\hline No & Sampel & $\begin{array}{l}\text { Pendapatan } \\
\text { (Rp/bulan) }\end{array}$ & Satuan & Standar & Eksisting \\
\hline \multirow[t]{3}{*}{1} & Nelayan & - & & & \\
\hline & a. Bermotor & 2.491 .994 & $\%$ & Naik & 6.21 \\
\hline & b. Tradisional & 719.394 & $\%$ & Naik & 5.33 \\
\hline \multirow[t]{3}{*}{2} & Petambak udang & - & & & \\
\hline & a. Tradisional & 21.839 .273 & $\%$ & Naik & 31.42 \\
\hline & b.Intensif & 3.875 .689 & $\%$ & Naik & 7.03 \\
\hline \multirow[t]{6}{*}{3} & Petani & - & & & \\
\hline & a. Tanam padi & 1.232 .466 & $\%$ & Naik & 14.69 \\
\hline & b. Perkebunan sawit & 3.141 .086 & $\%$ & Naik & 9.68 \\
\hline & c. Perkebunan karet & 1.685 .750 & $\%$ & Naik & 7.70 \\
\hline & d.Perkebunan kelapa & 2.416 .725 & $\%$ & Naik & 8.32 \\
\hline & e. Perkebunan coklat & 4.325 .575 & $\%$ & Naik & 5.61 \\
\hline \multirow[t]{3}{*}{4} & Pedagang & - & & & \\
\hline & a. Barang harian & 1.039 .974 & $\%$ & Naik & 6.45 \\
\hline & b. Hasil perikanan & 14.873 .810 & $\%$ & Naik & 23.21 \\
\hline
\end{tabular}




\begin{tabular}{|c|c|c|c|c|c|}
\hline & $\begin{array}{l}\text { c. Sarana produksi } \\
\text { perikanan }\end{array}$ & 208.036 & $\%$ & Naik & 12.12 \\
\hline & $\begin{array}{l}\text { d. Sarana produksi } \\
\text { pertanian }\end{array}$ & 561.194 & $\%$ & Naik & 32.00 \\
\hline & $\begin{array}{l}\text { e. Hasil pertanian } \\
\text { tanaman pangan }\end{array}$ & 2.464 .286 & $\%$ & Naik & 14.72 \\
\hline & f. Hasil perkebunan & 2.243 .810 & $\%$ & Naik & 11.54 \\
\hline & g.Pedagang kaki lima & 446.197 & $\%$ & Naik & 9.14 \\
\hline & h. Bahan bangunan & 5.376 .548 & $\%$ & Naik & 35.73 \\
\hline \multirow[t]{4}{*}{5} & Industri rumah tangga & - & & & \\
\hline & $\begin{array}{l}\text { a. Pengolahan ikan } \\
\text { asin }\end{array}$ & 868.774 & $\%$ & Naik & 4.15 \\
\hline & b. Penjual gorengan & 415.000 & $\%$ & Naik & 9.19 \\
\hline & c. Pembuatan atap nipa & 410.000 & $\%$ & Naik & 4.14 \\
\hline
\end{tabular}

\section{b. Tingkat Kemiskinan Kawasan Pesisir Kabupaten Batubara}

\begin{tabular}{|l|l|c|r|r|}
\hline No & lndikator & Satuan & Standar & Eksisting \\
\hline 1 & Tidak miskin & $\%$ & 100 & 62.92 \\
\hline 2 & Miskin & $\%$ & 0 & 31.09 \\
\hline 3 & Sangat Miskin & $\%$ & 0 & 5.99 \\
\hline
\end{tabular}

Sumber : Data Primer

\section{Tabel 3 : Kondisi Sosial Budaya di Kawasan Pesisir Kabupaten Batubara.}

\section{a. Kondis Pendidikan Di Kawasan Pesisir Kabupaten Batubara}

\begin{tabular}{|l|l|c|l|r|}
\hline No & lndikator & Satuan & Standar & Eksisting \\
\hline \multirow{4}{*}{1} & Fasilitas sekolah & & & \\
\cline { 2 - 5 } & a. Laboratorium & $\%$ & 100 & 6.67 \\
\cline { 2 - 5 } & b. Alat peraga guru & $\%$ & 100 & 3.33 \\
\cline { 2 - 5 } & c. Olah raga & $\%$ & 100 & 10.00 \\
\hline \multirow{4}{*}{2} & Disiplin guru & & & \\
\cline { 2 - 5 } & a. Lambat masuk & Waktu & Tepat waktu & 11.69 \\
\cline { 2 - 5 } & a. Sering tak masuk & Tugas & Masuk & 12.99 \\
\cline { 2 - 5 } & b. Tugas tidak diperiksa & Jam & Diterangkan & 16.99 \\
\cline { 2 - 5 } & c. Malas menerangkan & Jam & Dijelaskan & 25.97 \\
\cline { 2 - 5 } & d. Banyak mencatat & & & \\
\hline 3 & Disiplin murid & $\%$ & Ditegur & 13.33 \\
\cline { 2 - 5 } & a. Ditegur & & & \\
\hline
\end{tabular}




\begin{tabular}{|l|l|c|l|r|}
\hline & b.Dibiarkan & $\%$ & & 86.67 \\
\hline 4 & Penyebab putus sekolah & & & \\
\cline { 2 - 5 } & a. Jumlah putus sekolah & $\%$ & 0 & 21.00 \\
\cline { 2 - 5 } & b. Kemiskinan & $\%$ & Tidak ada & 45.16 \\
\hline & c. Kurang minat/tidak bermanfaat & $\%$ & Berminat & 16.13 \\
\hline & d. Malas & $\%$ & Rajin & 12.90 \\
\cline { 2 - 5 } & e. Jarak terlalu jauh & $\%$ & & 9.68 \\
\hline 5 & Tingkat pendidikan putus sekolah & & & \\
\cline { 2 - 5 } & a. Sekolah Dasar & $\%$ & 0 & 22.58 \\
\cline { 2 - 5 } & b.SLTP & $\%$ & 0 & 54.84 \\
\hline & c. SLTA & $\%$ & 0 & 22.58 \\
\hline \multirow{4}{*}{6} & Jenis Kelamin Putus Sekolah & & & \\
\cline { 2 - 5 } & a. Laki-laki & $\%$ & 0 & 38.71 \\
\cline { 2 - 5 } & b.Perempuan & $\%$ & 0 & \\
\hline
\end{tabular}

\section{b. Fasilitas dan Pelayanan Kesehatan}

\begin{tabular}{|l|l|c|c|r|}
\hline No & \multicolumn{1}{|c|}{ Indikator } & Satuan & Standar & Eksisting \\
\hline 1 & Sarana kesehatan & $\%$ & 100 & 0.75 \\
\hline 2 & Fasilitas Kesehatan & $\%$ & 100 & 0.75 \\
\hline 3 & Tenaga Medis & $\%$ & 100 & 38.95 \\
\hline 4 & Pelayanan Tenaga Medis & & & \\
\hline \multirow{2}{*}{} & a. Tidak Puas & $\%$ & 100 & 48.69 \\
\cline { 2 - 5 } & b. Kurang Puas & $\%$ & 100 & 42.32 \\
\cline { 2 - 5 } & c. Sangat Puas & $\%$ & 100 & 1.50 \\
\hline
\end{tabular}

Sumber : Data Primer

\section{Tabel 4 : Kondisi Pembangunan Berkelanjutan di Kawasan Pesisir Kabupaten Batubara.}

\section{a. Degredasi Lingkungan Kawasan Pesisir Kabupaten Batubara}

\begin{tabular}{|l|l|c|c|r|}
\hline No & lndikator & Satuan & Standar & Eksisting \\
\hline 1 & $\begin{array}{l}\text { Alat tangkap tidak ramah } \\
\text { lingkunagan }\end{array}$ & Unit & 0 & Banyak \\
\hline 2 & Pembuatan fishing ground & kali & 0 & Sering \\
\hline 3 & Alih fungsi hutan bakau & & & \\
\cline { 2 - 5 } & a. Faslitas umum & $\%$ & 0 & 23,36 \\
\cline { 2 - 5 } & b. Perkebunan & $\%$ & 0 & 45,31 \\
\cline { 2 - 5 } & c. Pertanian/sawah & $\%$ & 0 & 6,7 \\
\cline { 2 - 5 } & d. Perikanan & $\%$ & 0 & 24,62 \\
\hline
\end{tabular}




\begin{tabular}{|l|l|l|c|r|}
\hline 4 & Kugunaan kayu bakau & & & \\
\cline { 2 - 5 } & a. Kayu bakar & $\%$ & 0 & 69,29 \\
\cline { 2 - 5 } & b. Bahan bangunan & $\%$ & 0 & 15,36 \\
\cline { 2 - 5 } & c. Bahan baku arang & $\%$ & 0 & 15,36 \\
\hline \multirow{5}{*}{5} & Jalur hijau & & & \\
\cline { 2 - 5 } & a. Gundul & $\%$ & 0 & 25,16 \\
\cline { 2 - 5 } & b. Sedikit & $\%$ & 0 & 81,66 \\
\cline { 2 - 5 } & c. Banyak & $\%$ & 100 & 6,82 \\
\hline
\end{tabular}

b. Marketing Margin Beberapa Komuditi Kawasan Pesisir Kabupaten Batubara

\begin{tabular}{|l|l|c|c|r|}
\hline No & \multicolumn{1}{|c|}{ Indikator } & Satuan & Standar & Eksisting \\
\hline 1 & Gabah kering panen & $\%$ & 30 & 12,19 \\
\hline 2 & Sawit & $\%$ & 30 & 7,89 \\
\hline 3 & Karet & $\%$ & 30 & 18,92 \\
\hline 4 & Kelapa & $\%$ & 30 & 25,00 \\
\hline 5 & Coklat & $\%$ & 30 & 13,95 \\
\hline 6 & Ikan segar & $\%$ & 30 & 27,14 \\
\hline 7 & Ikan olahan & & 47,06 \\
\hline
\end{tabular}

\section{c. Penyebab Terjadinya Konflik Kawasan Pesisir Kabupaten Batubaru.}

\begin{tabular}{|l|l|c|l|r|}
\hline No & \multicolumn{1}{|c|}{ Indikator } & Satuan & \multicolumn{1}{c|}{ Standar } & Eksisting \\
\hline 1 & Kejadian konflik per tahun & & & \\
\hline \multirow{4}{*}{} & a. Sering & $\%$ & Tidak pernah & 36.32 \\
\cline { 2 - 5 } & b.Jarang & $\%$ & Tidak pernah & 63.68 \\
\cline { 2 - 5 } & c. Tidak pernah & $\%$ & Tidak pernah & 0 \\
\hline \multirow{5}{*}{2} & Penyebab konflik perikanan & & & \\
\cline { 2 - 5 } & a. Alat tangkap & $\%$ & Tidak ada & 79.17 \\
\cline { 2 - 5 } & b. Areal penangkapan & $\%$ & Tidak ada & 13.89 \\
\cline { 2 - 5 } & c. Musim tangkap & $\%$ & Tidak ada & 2.78 \\
\cline { 2 - 5 } & d.Pembagian hasil & $\%$ & Tidak ada & 4.17 \\
\hline \multirow{3}{*}{3} & Penyebab konflik pertanian & & & \\
\cline { 2 - 5 } & a. Batas tanah & $\%$ & Tidak ada & 57.14 \\
\cline { 2 - 5 } & b. Bagi hasil & $\%$ & Tidak ada & 42.87 \\
\hline
\end{tabular}




\section{d. Partisipasi Masyarakat Kawasan Pesisir Kabupaten Batubaru}

\begin{tabular}{|c|c|c|c|c|}
\hline No & Indikator & Satuan & Standar & Eksisting \\
\hline \multirow[t]{4}{*}{1} & Dalam perencanaan & & & \\
\hline & a. Tidak dilibatkan & $\%$ & Tidak pernah & 73.03 \\
\hline & b.Sedikit terlibat & $\%$ & Tidak pernah & 17.23 \\
\hline & c. Ikut terlibat & $\%$ & Tidak pernah & 9.74 \\
\hline \multirow[t]{3}{*}{2} & Pengawasan & & & \\
\hline & a. Ikut mengawas & $\%$ & Ikut & 13.73 \\
\hline & b. Tidak ikut mengawas & $\%$ & Ikut & 86.27 \\
\hline \multirow[t]{4}{*}{3} & pelaksanaan & & & \\
\hline & a. Tidak terlibat dalam pelaksanaan & $\%$ & Ikut & 73.78 \\
\hline & a. Kurang terlibat & $\%$ & Ikut & 19.85 \\
\hline & b.Ikut terlibat & $\%$ & Ikut & 6.37 \\
\hline \multirow[t]{4}{*}{4} & Manfaat dari pembangunan & & & \\
\hline & a. Tidak bermanfaat & $\%$ & Bermanfaat & 7.49 \\
\hline & b. Kurang bermanfaat & $\%$ & Bermanfaat & 80.15 \\
\hline & c. bermanfaat & $\%$ & Bermanfaat & 12.36 \\
\hline \multirow[t]{4}{*}{5} & Tanggapan terhadap pemerintah & & & \\
\hline & a. Tidak di tanggapi & $\%$ & Ditanggapi & 86.14 \\
\hline & b. Kurang di tanggapi & $\%$ & Ditanggapi & 9.74 \\
\hline & c. Di tanggapi & $\%$ & Ditanggapi & 4.12 \\
\hline
\end{tabular}

Sumber : Data Primer

Dari tiga unsur yang saling berkaitan, aspek sosial budaya merupakan aspek yang sangat menentukan (determinan) dalam pembangunan berkelanjutan di kawasan pesisir kabupaten Batubara. Hal ini disebabkan oleh kearifan lokal yang sudah ditinggalkan sehingga menimbulkan degredasi lingkungan, kedisiplinan guru dan murid yang rnenyebabkan mutu pendidikan rendah, sehingga menyebabkan kemiskinan, serta kepedulian pemerintah yang kurang perhatian terhadap pembangunan berkelanjutan.

Kalau pembangunan hanya melihat secara parsial dari masingmasing unsur pembangunan maka pembangunan tidak akan berkelanjutan untuk lebih jelasnya hubungan dari masing-masing unsur adalah; jika pembangunan hanya memperhatikan aspek sosial dan ekonomi maka hasilnya hanya untuk pemerataan, jika pembangunan memperhatikan lingkungan dan sosial hasil yang akan 
dicapai hanya untuk kenyamanan sedangkan pembangunan yang memperhatikan ekonomi dan lingkungan hasilnya untuk pertumbuhan akan tetapi lingkungan akan menanggung beban.

\section{KESIMPULAN}

Secara urnum penelitian ini menyimpulkan antara lain:

1. Pembangunan kawasan pesisir kabuputen Batubara belum menerapkan konsep dan prinsip pembangunan berkelanjutan. Hal ini dapat dibuktikan dari:

a. Pembangunan belum dijumpai yang dilaksanakan program konsenvasi mengakibatkan lingkungan, degradasi sehingga lingkungan generasi yang akan datang tidak akan dapat menikmati seperti ini.

b. Pembangunan belum dapat mengentaskan kemiskinan dan menciptakan pernerataan pendapatan dan lapangan kerja baru.

c. Tingkat pendidikan masyarakat masih rendah, kelembagaan yang ada tidak mengacu pada pembangunan berkelanjutan, serta adanya pergeseran budaya yang selama ini menjaga lingkungan dengan kearifan lokal, tetapi saat ini ditinggalkan dan kalau masih ada lebih banyak pada segi serimonialnya bukan kepada konservasinya.Pembangunan berkelanjutan di kawasan pesisir kabupaten Batubara hanyalah sebatas konsep di atas kertas yang belum diaplikasikan/diterapkan di lapangan.

2. Pembangunan di kawasan pesisir kabupaten Batubara dapat berkelanjutan dengan cara merencanakan penggunaan sumberdaya alam sebagai sumber ekonomi untuk menciptakan kesejahteraan masyarakat saat ini dan generasi yang akan datang. Sebagai dasar perencanaannya dapat digunakan hasil kajian ini, termasuk dalam menyusun perencanaan strategis.

Sedangkan secara khusus penelitian ini menyimpulkan :

1. Aspek Lingkungan berpengaruh positif terhadap aspek ekonomi dalam mendukung pembangunan berkelanjutan. Pengaruh 
lingkungan yang dominan terhadap ekonomi adalah penggunaan sumberdaya alam/lingkungan yang tidak efisien, eksploitasi sumberdaya alam yang melebihi daya dukung sehingga akan mempengaruh terhadap perekonomian masyarakat kawasasan pesisir dalam jangka panjang (generasi masa depan).

2. Aspek sosial budaya berpengaruh positif terhadap aspek/lingkungan dalam mendukung pembangunan berkelanjutan. Adanya kerusakan lingkungan kawasan pesisir Batubara saat ini banyak disebabkan oleh rendahnya tingkat pengetahuan masyarakat, prilaku masyarakat, lemahnya penerapan peraturan dan perundangan yang ada serta kurangnya lembaga pengawasan.

3. Aspek sosial budaya tidak berpengaruh negatif terhadap aspek ekonomi dalam mendukung pembangunan berkelanjutan. Terjadinya hubungan negative ini disebabkan oleh sifat, sikap dan prilaku masyarakatnya. Mereka lebih banyak menerima dari pada memberi manfaat kepada keberlangsungan komponen sumberdaya alam yang merupakan sumber pendapatan mereka.

4. Aspek lingkungan, aspek ekonomi dan aspek sosial mempengaruhi pembangunan berkelanjutan. Kontribusi terbesar terhadap pembangunan berkelanjutan adalah aspek ekonomi kemudian diikuti aspek lingkungan dan yang kecil adalah aspek sosial budaya, aspek ini memberi hubungan negative terhadap pembangunan berkelanjutan. Permasalahan pembangunan berkelanjutan kawasan pesisir kabupaten Batubara adalah kurangnya kepedulian pemerintah dan masyarakat terhadap daya dukung yang akan mempengaruhi sumberdaya alam sebagai sumberdaya ekonomi.

\section{DAFTAR PUSTAKA}

Adi. W. 2007. Pembangunan Berkelanjutan, Tinjauan Teoritis dan Empiris. Pusat Penelitian Ekonomi. LIPI, Jakarta. 412 hal.

Adisasmita, R. 2006. Pembangunan Kelautan dan Kewilayahan. Graha llmu, Yogyakarta. 270 hal. 
Adiwijoyo S. 2005. Konsilidasi Wawasan Maritim Indonesia. Pakar, Jakarta. 160 hal.

Ahmad, M. 2008. Hasrat Berprestasi sebagai Motivasi pembangunan. Makalah narasumber pada "Workshop Penguatan Kapasitas dalam Penyusunan Rencana Pembangunan Jangka Menengah Kecamatan untuk Kabupaten/Kota di Provinsi Riau " pada tanggal 29 Juli 2008 di Pekanbaru. 8 hal.

- dan Nurmatias. 2008. Kajian Potensi Perikanan Tangkap Kabupaten Langkat. Dinas Perikanan dan Kelautan Kab. Langkat. Stabat.

Dahril T. 1995. Potensi Alam dan Sumberdaya Insani. Universitas Islam Riau Press, Pekanbaru. 151 hal.

Dinas Perikanan dan Kelautan, 2009. Statistik Perikanan dan Kelautan Kabupaten Batubara. Dinas Perikanan dan Kelautan Kabupaten Batubara, Limapuluh.

Undang-undang No. 27. Tahun 2007. Tentang Pengelolaan Wilayah Pesisir dan Pulau-pulau Kecil. Fokusmedia, Bandung. 94 hal.

Yayasan SPES. 1992. Pembangunan Berkelanjutan. Mencari Format Politik. PT. Gramedia Pustaka Utama. Jakarta. 402 hal.

Ahmad, M. 2004. Perikanan di Kelurahan Purnama, Kota Dumai. Jurnal Perairan. Volume 2 Nomor 2 Desember 2004.

-------------. 2008. Modernisasi desa Pantai dan Upaya Pengentasan Kemiskinan Nelayan Melalui Program Kredit dan Motorisasi: Jurnal Gading. Volume 1 No. 1, April 2008.

Tarigan. K.1993. Pengaruh Motorisasi Penangkapan Ikan Terhadap Tingkat dan Ketimpangan Pendapatan nelayan di Sumatera Utara. Jurnal Terubuk. Tahun XIX, Nomor 55 Februari 1993.

Yudi Wahyudi, 2003. Sistem Budaya Ekonomi Masyarakat Pesisir. Jurnal PKSPL-IPB, Desember 2003. 